\title{
How Often Does Femoroacetabular Impingement Occur After an Innominate Osteotomy for Acetabular Dysplasia?
}

\author{
Pablo Castañeda MD, Carlos Vidal-Ruiz MD, Alfonso Méndez MD, \\ Diego Pérez Salazar MD, Armando Torres MD, MSc, FACS
}

Published online: 28 January 2016

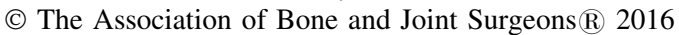

\begin{abstract}
Background Femoroacetabular impingement is increasingly recognized as a cause of hip pain but its incidence after an innominate osteotomy for the correction of acetabular dysplasia has not been determined. This information would be essential for the orthopaedic surgeon because it has the potential to produce a poor outcome in
\end{abstract}

One of the authors (AT) has received personal fees from Pfizer (New York, NY, USA) as a consultant and speaker.

All ICMJE Conflict of Interest Forms for authors and Clinical Orthopaedics and Related Research ${ }^{(\mathbb{R}}$ editors and board members are on file with the publication and can be viewed on request.

Clinical Orthopaedics and Related Research ${ }^{\mathbb{R}}$ neither advocates nor endorses the use of any treatment, drug, or device. Readers are encouraged to always seek additional information, including FDAapproval status, of any drug or device prior to clinical use.

Each author certifies that his or her institution approved the human protocol for this investigation, that all investigations were conducted in conformity with ethical principles of research, and that informed consent for participation in the study was obtained.

This work was performed at Shriners Hospital for Children, Mexico City, Mexico.

Electronic supplementary material The online version of this article (doi:10.1007/s11999-016-4721-7) contains supplementary material, which is available to authorized users.

P. Castañeda ( $₫)$, A. Méndez

Shriners Hospital for Children, Av. Del Iman 257, Del.

Coyoacán, Mexico City, Mexico

e-mail: pablocastaneda@me.com

C. Vidal-Ruiz

Hospital German Díaz Lombardo, Mexico City, Mexico

D. P. Salazar, A. Torres

American British Cowdray Medical Center, Mexico City 04600, Mexico the long term when trying to balance acetabular instability and overcorrection.

Questions/purposes The purposes of our study were (1) to determine the frequency with which clinically relevant femoroacetabular impingement (FAI) occurs after an innominate osteotomy for the treatment of acetabular dysplasia; (2) to determine risk factors for the development of FAI; and (3) to compare postoperative radiographic and clinical outcomes in patients having undergone an innominate osteotomy for the correction of acetabular dysplasia both with and without FAI.

Methods This was a retrospective review of 154 hips (132 patients) that had undergone an innominate osteotomy for acetabular dysplasia and were evaluated at a minimum followup of 10 years (mean $=12$ years). Mean age at the time of surgery was 3 years, 114 hips had a concomitant open reduction, and 54 hips also had femoral shortening. One hundred eight hips had a Salter osteotomy and 46 had a Pemberton osteotomy. Radiographs were analyzed to determine the lateral center-edge angle (CE angle) and the presence of a crossover sign. The diagnosis of FAI was established when the CE angle was greater than $40^{\circ}$, there was a positive crossover sign, and the patient had groin pain when flexing the hip less than $90^{\circ}$. Comparisons between nonparametric variables were performed with a Mann-Whitney's U test. Categorical variables were compared with a chi-square test. Change in acetabular index (correction) was dichotomized considering $20^{\circ}$ of correction as the cutoff point. Association is presented as odds ratio (95\% confidence interval), and logistic regression was performed.

Results According to our criteria, 18 of 154 hips had FAI $(12 \%)$. Of the 18 patients with FAI, 10 had undergone a Pemberton osteotomy (10 of 46 [22\%]) and eight a Salter osteotomy (eight of 108 [7\%]). A change in the 
postoperative acetabular index greater than $20^{\circ}$ was associated with a greater likelihood of developing FAI. The mean postoperative acetabular index was lower for the group with FAI, for whom it was $20^{\circ}$, compared with the group without FAI, for whom it was $27^{\circ}(\mathrm{p}=0.04)$. The mean Iowa Hip Score for the group with FAI was 85, whereas for those without FAI, it was $93(\mathrm{p}=0.03)$.

Conclusions FAI is not common after an innominate osteotomy for the treatment of acetabular dysplasia; however, overcorrection is related to a higher incidence. When FAI is present, it can affect the outcome. Overcorrection should be avoided when performing an innominate osteotomy for the treatment of acetabular dysplasia because it can create iatrogenic FAI and have an adverse effect on outcome.

Level of Evidence Level III, therapeutic study.

\section{Introduction}

It is widely recognized that pathologic conditions of the hip in adolescent and young adult patients may cause permanent hip osteoarthritis (OA) and associated long-term disability. There is a spectrum of morphologic abnormality that includes both dysplasia/instability and femoroacetabular impingement (FAI), which are two pathomechanisms that result in most problematic hip disorders in adolescents and young adults $[7,9,14,16,19,22,27]$. Currently, structural damage to articular cartilage and the chondrolabral complex is believed to be the primary abnormality in the etiology of hip OA $[1,7,9,16,17,20,22,27,28]$. The mechanical theory of OA postulates that the acetabular rim, labrum, and adjacent articular cartilage serve as the initial site of structural damage. Structural damage of the articulating surfaces of the hip initially occurs secondary to instability, impingement, or both.

Two of the most commonly used procedures for the correction of acetabular dysplasia are the innominate osteotomy described by Salter [25] and the pericapsular osteotomy described by Pemberton [21]. The rationale for the Salter osteotomy is stabilization of the reduced hip in the position of function by redirecting the misdirected acetabulum; the coverage of the lateral part of the femoral head (translated into a reduction in the acetabular index) is typically increased a mean of $12^{\circ}$. Rab [23] developed a mathematical model for the Salter osteotomy that predicted a theoretical improvement in the acetabular index of approximately $10^{\circ}$. The positive biomechanical influence of a well-centered, stabilized hip on secondary maturation and normal development of the hip has been documented in most studies with long-term followup. The pericapsular osteotomy described by Pemberton is based on the principle of reshaping the dysplastic acetabulum and similarly good long-term results have been described [31]. There does remain, however, a potential for overcorrection and iatrogenic FAI with either of these procedures.

The ultimate factors that predispose certain hips to develop degenerative changes remain uncertain $[2,4,13]$. We are concerned that overcorrection and the resulting reduction of clearance between the femoral head and the acetabulum may be one such factor. However, few studies have evaluated the presence of FAI after innominate osteotomy procedures, and it remains unknown whether the presence of FAI is clinically relevant [13].

We therefore sought (1) to determine the frequency with which clinically relevant FAI occurs after an innominate osteotomy for the treatment of acetabular dysplasia; (2) to determine risk factors for the development of FAI; and (3) to compare postoperative radiographic and clinical outcomes in patients having undergone an innominate osteotomy for the correction of acetabular dysplasia both with and without FAI.

\section{Patients and Methods}

We performed a retrospective study of 132 patients (154 hips) who underwent an innominate osteotomy for acetabular dysplasia at a minimum followup of 10 years (mean $=12$ years) $($ Appendix 1 [Supplemental materials are available with the online version of $C O R R^{\circledR}$.]). Between January 2000 and December 2004, 316 patients (398 hips) with a diagnosis of acetabular dysplasia underwent surgical correction in a single institution by one of two experienced pediatric orthopaedic surgeons (NC, PC). Cases in which varus or derotation osteotomies had been performed were not included and the patients who had undergone revision surgery were excluded. Thus, 154 hips were available for clinical and radiographic followup at a minimum of 10 years. The mean age at the time of surgery was 3 years (and their mean age at the time of final followup was 15 years), 114 hips had a concomitant open reduction, and 54 hips also had femoral shortening; the indication for the open reduction was when the hip was considered to be dislocated and the femoral shortening was performed when the reduction was considered to be too tight without it. However, this was the individual surgeon's criteria. One hundred eight hips had a Salter osteotomy and 46 had a Pemberton osteotomy; this was also dependent on surgeon criteria. The procedures were all carried out through a standard anterior modified Smith-Petersen approach with a standard technique. Most of the hips ( $\mathrm{n}=$ 114) underwent a concomitant open reduction in addition to the innominate osteotomy; this was performed when it was considered that the hip was dislocated as indicated by a Tönnis grade of dislocation of II or greater. Fifty-four also 
had femoral shortening when it was deemed that the reduction was too tight. These decisions were consistent between surgeons but varied on an individual basis for each case. The femoral shortening was performed through a separate lateral approach and in all cases was fixed with a standard four-hole locking compression plate; the amount of femoral shortening was not recorded and varied according to each case. No intentional derotation was performed in these cases. Both surgeons use the technique of performing the first femoral cut, reducing the joint, and shortening the amount of overlap found. Patients were placed in a one-leg spica cast for 6 weeks after the surgery and were subsequently placed in a part-time Denis-Browne abduction splint at night for 3 months. No specific physical therapy was indicated. The mean postoperative acetabular index for the patients undergoing a Pemberton osteotomy was $23^{\circ}$ and for the patients undergoing a Salter osteotomy, it was $26^{\circ}$.

All of these patients were seen and evaluated clinically by one of three independent examiners who had not been involved in the original treatment (AM, CV-R, DPS) and radiographs were taken at final followup.

Radiographs were analyzed to determine the lateral center-edge angle or center-edge angle of Wiberg [32] obtained from an AP pelvic radiograph and used to assess the superolateral coverage of the femoral head by the acetabulum. It was calculated by measuring the angle between two lines: (1) a line through the center of the femoral head, perpendicular to the transverse axis of the pelvis; and (2) a line through the center of the femoral head, passing through the most superolateral point of the sclerotic weightbearing zone of the acetabulum. Values of $<25^{\circ}$ may indicate inadequate coverage of the femoral head, whereas values of $>40^{\circ}$ may indicate overcoverage [30].

With use of an AP view of the pelvis, all acetabula can be labeled as retroverted or anteverted on the basis of the presence or absence of a crossover or figure-of-eight sign. An acetabulum is considered to be anteverted if the line of the anterior aspect of the rim does not cross the line of the posterior aspect of the rim before reaching the lateral aspect of the sourcil and retroverted if the line of the anterior aspect of the rim does cross the line of the posterior aspect of the rim before reaching the lateral edge of the sourcil [3]. This can be a difficult determination to make, and it requires careful assessment of the film quality, because a large element of error may be introduced by excessive pelvic tilt or rotation or a lack of clarity of the anterior and posterior acetabular margins. Detection of the posterior aspect of the rim inferiorly at the transition to the ischium can facilitate distinction between the anterior and posterior margins. Prominent extension of the ischial spine into the pelvis is an additional finding that is associated with acetabular retroversion. It should be noted that true acetabular retroversion is associated with a deficient posterior wall (the center of the femoral head is lateral to the posterior aspect of the hip), whereas anterior overcoverage refers to the hip with a crossover sign but no posterior wall deficiency. We used the definition of a positive crossover sign described by Tannast et al. [29], which has been proven to be reliable $[10,15]$. The radiographic diagnosis of FAI was established when the center-edge (CE) angle was greater than $40^{\circ}$ and there was a positive crossover sign.

Clinical evaluation was performed with the Iowa Hip Score and the presence of a positive impingement sign was looked for; the clinical diagnosis of FAI was considered when the patient had groin pain when flexing the hip less than $90^{\circ}$ and rotating internally less than $15^{\circ}$. This evaluation was done by one of three investigators (AM, CV-R, DPS) who are orthopaedic surgeons and were not involved in the treatment of these patients.

Of the entire cohort of 154 patients, at the time of final followup, it was found that 10 had pain on activities of daily living and 15 referred pain on exertion. The mean Iowa Hip Score for the 114 patients undergoing an open reduction was 87 compared with 90 for the 40 hips that only had the innominate osteotomy and 84 for the 54 who also underwent femoral shortening $(\mathrm{p}=0.03$ and 0.04 , respectively). The mean Iowa Hip Score for the 108 patients who underwent a Salter osteotomy was not different from those who underwent a Pemberton osteotomy (90 versus $88 ; \mathrm{p}=0.05$ ).

\section{Statistical Analysis}

Continuous variables were tested for normality (Kolmogorov-Smirnov). All were nonparametric and are described as median (interquartile range, minimum-maximum). Categorical variables are described as absolute frequencies (percentage). Comparisons between nonparametric variables were performed with a Mann-Whitney's U test. Categorical variables were compared with a chisquare test. Change in acetabular index (correction) was dichotomized considering $20^{\circ}$ of correction as the cutoff point. Association is presented as odds ratio (95\% confidence interval). A logistic regression model was performed. An omnibus test was used to select between models. Change in acetabular index alone was the best model. The Hosmer and Lemeshow test was used to assess its goodness of fit. Analysis was performed with SPSS Version 20.0 (IBM Corp, Armonk, NY, USA), R Statistical Software (Version 3.1.0: A language and environment for statistical computing; R Foundation for Statistical Computing, Vienna, Austria), and Rcmdr package (Version 2.0-4, Fox 
J, McMaster University, Canada, Hamilton, Ontario, Canada). A p value $\leq 0.05$ was considered statistically significant.

\section{Results}

According to our criteria, 18 of 154 hips had FAI, which represents a frequency of $12 \%$. Forty-two patients had a CE angle greater than $40^{\circ}$ and the same 42 patients had a crossover sign; however, of these 42 patients, only 18 had groin pain on flexion of the hip below $90^{\circ}$ and internal rotation of less than $15^{\circ}$.

After assessing the importance of variables such as sex, age, and preoperative acetabular index, we found that none were significant confounders; change (correction) in acetabular index itself resulted in a B coefficient of -0.049 $(\operatorname{Exp}[\mathrm{B}]=0.952 ; 95 \%$ confidence interval $[\mathrm{CI}], 0.907)$ and a change (correction) in the acetabular index greater than 20 was associated with an increased likelihood of a patient developing symptomatic FAI (odds ratio, 2.197; 95\% CI, 1.154-4.180; $\mathrm{p}=0.015)$.

The mean CE angle for the entire cohort was $32^{\circ}$; for the 114 patients undergoing an open reduction, it was $32^{\circ}$ and was the same as for the 40 hips that only had the innominate osteotomy $(p=0.06)$. The mean final CE angle for the 108 patients who underwent a Salter osteotomy was $31^{\circ}$ compared with $34^{\circ}$ for the 46 patients who had a Pemberton osteotomy $(\mathrm{p}=0.05)$. The mean immediate postoperative acetabular index after osteotomy was lower in the group with FAI than in the group without FAI $\left(20^{\circ} \pm\right.$ $2^{\circ}$ versus $\left.27^{\circ} \pm 3^{\circ}, \mathrm{p}=0.004\right)$. There was no difference in the rate of FAI by age or sex and the groups were homogenous (Table 1). The only statistically significant finding was the postoperative acetabular index with the group who presented FAI having a mean acetabular index (AI) of $20^{\circ}$ compared with the group without FAI for whom it was $22^{\circ}$ (Table 2; Figs. 1, 2, 3). We found that FAI occurred more than twice as often when the correction in AI was greater than $20^{\circ}$ (Table 3). As expected, hip scores were lower in patients with FAI than those without FAI. The mean Iowa Hip Score for the group with FAI was 85, whereas for those without FAI, it was $93(\mathrm{p}=0.03)$ (Table 4).

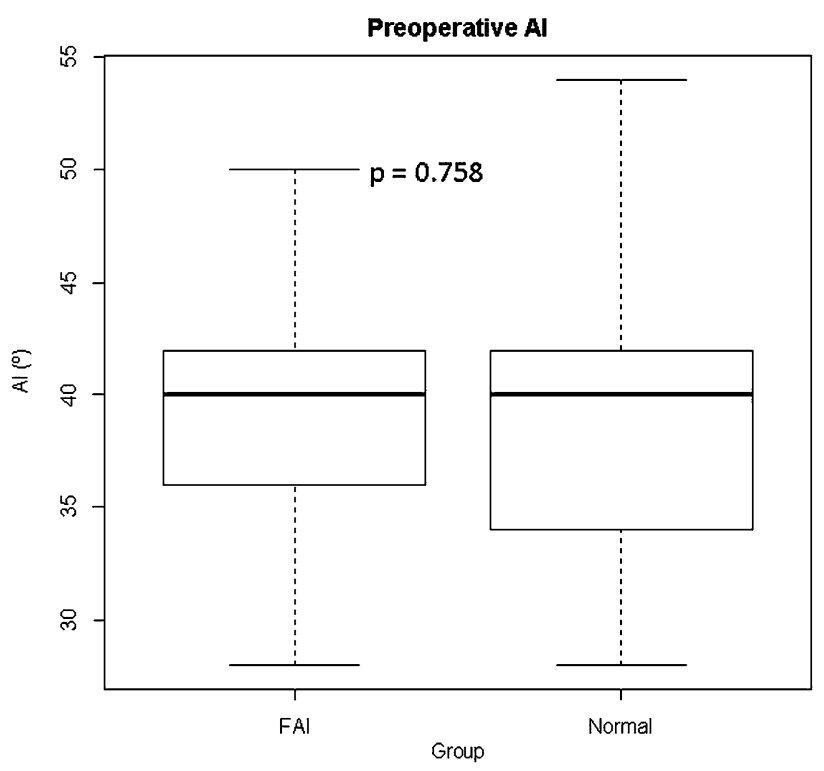

Fig. 1 Difference in preoperative AI between the group that ultimately presented FAI and the one that did not.

Table 1. Characteristics of the sample

\begin{tabular}{llll}
\hline Characteristic & Group: FAI $(\mathrm{n}=59)$ & Group: normal $(\mathrm{n}=169)$ & $\mathrm{p}$ value* \\
\hline Age (years) & $2.5(1.0,1.4-6.0)$ & $2.5(1.6,1.3-8.3)$ & 0.894 \\
Female sex & $51(86.4 \%)$ & $155(91.7 \%)$ & 0.237 \\
\hline
\end{tabular}

Values presented as median (interquartile range, minimum-maximum), absolute frequency (\%); * Mann-Whitney's U test, chi-square test; $\mathrm{FAI}=$ femoroacetabular impingement.

Table 2. Difference in $\mathrm{AI}$

\begin{tabular}{lllll}
\hline Acetabular index & Group: FAI $(\mathrm{n}=59)$ & Group: normal $(\mathrm{n}=169)$ & Difference & $\mathrm{p}$ value* \\
\hline Preoperative & $40(6,28-50)$ & $40(8,28-54)$ & 0 & 0.758 \\
Postoperative & $20(6,2-32)$ & $22(5,10-40)$ & 2 & 0.056 \\
Change & $18(10,6-42)$ & $16(8,4-34)$ & 2 & 0.063 \\
\hline
\end{tabular}

Values presented as median (interquartile range, minimum-maximum); * Mann-Whitney's $\mathrm{U}$ test; AI $=$ acetabular index; FAI $=$ femoroacetabular impingement. 


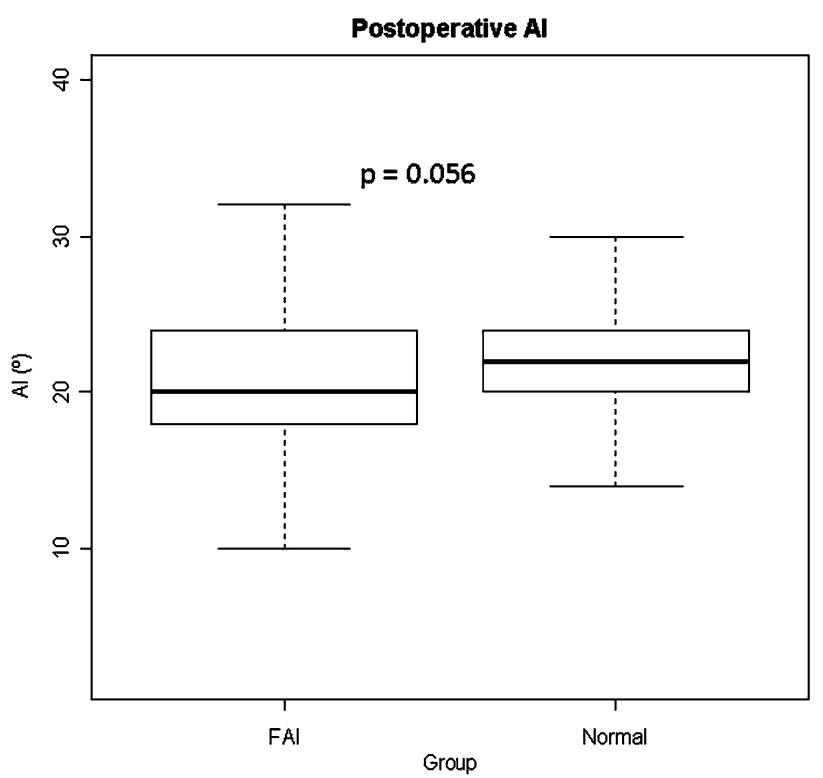

Fig. 2 Difference in postoperative AI between the group that ultimately presented FAI and the one that did not.

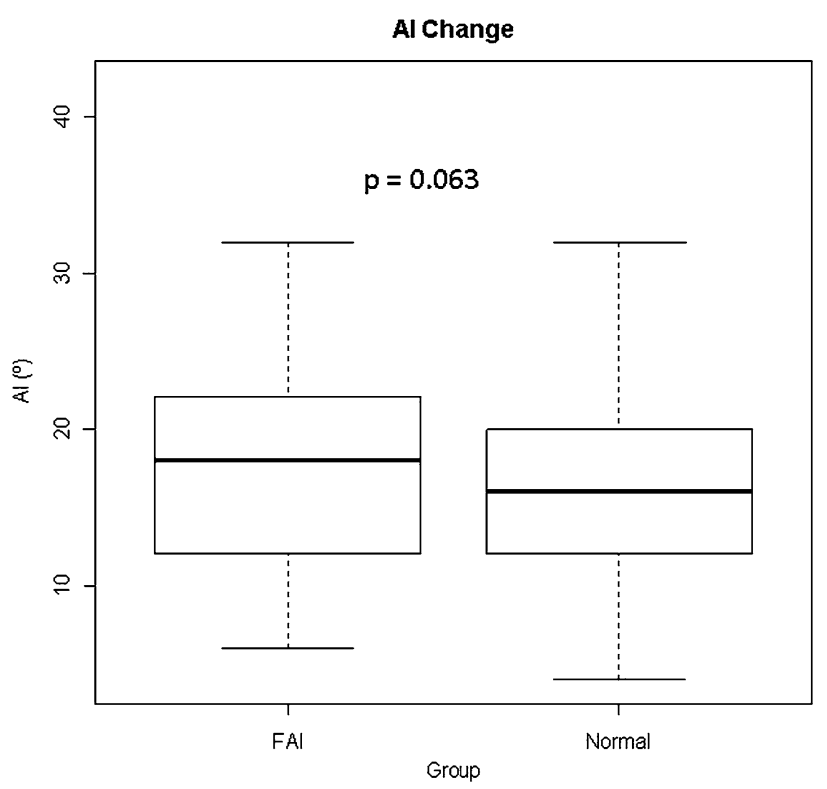

Fig. 3 Difference in the change of the acetabular index between the group that ultimately presented FAI and the one that did not.

\section{Discussion}

In the principles of treatment of hip dysplasia outlined by Salter [26], the correction of bony deformity to improve hip stability was well documented; and although the condition of abnormal abutment between the femoral head and the acetabulum had been recognized many years before, it was only until fairly recently that the condition known as FAI was truly recognized as an independent pathological condition. The treatment of acetabular dysplasia must take into account this delicate balance between instability and overcorrection. Although the principle of improving the bony coverage is easily understood, it is easy to overcorrect and produce FAI. It has been proven that static factors resulting in abnormal stress and load between the femoral head and the acetabulum lead to asymmetric wear of the chondral surfaces of both the acetabulum and the femoral head, and this can be accentuated when dynamic stress results in abnormal contact between the femoral head and acetabular rim.

The presence of acetabular retroversion after an innominate osteotomy is a well-known phenomenon; Salter's innominate osteotomy predisposes to retroversion because it hinges on the symphysis pubis [18]. It has been postulated, however, that this acetabular version will remodel by skeletal maturity.

The radiographic results of innominate osteotomies in the frontal plane have been well outlined [5, 6, 8]; however, the evaluation in the transverse plane, especially evaluation of retroversion, is less understood.

Our results are similar to those of Dora et al. [11] who found acetabular retroversion to be present in

Table 4. Logistic regression model classification table

\begin{tabular}{llll}
\hline Observed & \multicolumn{2}{l}{ Predicted } & \\
\cline { 2 - 3 } & FAI & Normal & Percent correct \\
\hline FAI & 1 & 58 & 1.7 \\
Normal & 0 & 169 & 100.0 \\
Overall percent correct & & 74.6 \\
\hline
\end{tabular}

Logistic regression: $\mathrm{B}=-0.049, \operatorname{Exp}(\mathrm{B})=0.952(95 \%$ confidence interval, 0.907-0.999; $\mathrm{p}=0.043)$; constant : $\mathrm{B}=1.913$, $\operatorname{Exp}(\mathrm{B})=$ $6.773(\mathrm{p}<0.001) ; \mathrm{FAI}=$ femoroacetabular index.

Table 3. Association between AI correction $>20^{\circ}$ and FAI

\begin{tabular}{llll}
\hline Change in acetabular index & $\begin{array}{l}\text { Group: FAI } \\
(\mathrm{n}=59)\end{array}$ & $\begin{array}{l}\text { Group: normal } \\
(\mathrm{n}=169)\end{array}$ & OR (95\% CI) \\
\hline $\mathrm{AI}>20^{\circ}$ & $22 / 59(37.3 \%)$ & $36 / 169(21.3 \%)$ & $2.197(1.154-4.180)$ \\
\hline
\end{tabular}

Values presented as absolute frequency $(\%) ; *$ Chi-square test $\mathrm{FAI}=$ femoroacetabular impingement; $\mathrm{AI}=$ acetabular index; OR = odds ratio; $\mathrm{CI}=$ confidence interval. 
approximately one-third of patients who had undergone either a Salter or Le Coeur osteotomy.

Understanding the morphology of the acetabulum AP view of the pelvis can be difficult. The mouth of the acetabular opening spirals gradually into increasing anteversion from the proximal part to the distal part of the acetabulum; at the proximal part, the acetabular dome has a mean anteversion of $4^{\circ}$ (with $95 \%$ being between $2^{\circ}$ and $5^{\circ}$ ) [24]; at the equator of the femoral head, the mean version is $20^{\circ}$. The most relevant site is in the proximal third of the acetabulum where ROM by impingement can occur when there is overcoverage. Provided the pelvic radiograph is orthograde, we can assume version of the acetabular dome by evaluating the anterior and posterior borders of the acetabulum and their relationship, considered to be normal if both lines join together at the lateral edge of the acetabular roof.

FAI is not common after an innominate osteotomy for the treatment of acetabular dysplasia; however, overcorrection is related to a higher incidence. When FAI is present, it can affect the outcome. Overcorrection should be avoided when performing an innominate osteotomy for the treatment of acetabular dysplasia because it can create iatrogenic FAI and have an adverse effect on outcome.

\section{Limitations}

This study has major limitations, the most important one being that as a result of being a retrospective review, there are a number of confounding variables that were uncontrollable. The definition of FAI is somewhat subjective and the criteria for defining it are subject to individual interpretation. However, this introduces the risk of information bias, but we reduced this risk for our study by defining FAI strictly as a combination of clinical impingement defined by having groin pain when flexing the hip less than $90^{\circ}$ and rotating internally less than $15^{\circ}$ and radiographic signs defined by having a $\mathrm{CE}$ angle greater than $40^{\circ}$ and a positive crossover sign.

There is potential for selection bias because the completeness of followup and case ascertainment differed between the groups; however, the high level of followup minimizes this risk. We believe that this is medical surveillance bias and is excluded by the fact that our groups underwent the same procedures. There is also potential for information bias because the validity of our methods for diagnosing FAI has not been established. This is something for the medical community to work on the future because a clear definition of what constitutes clinically relevant FAI should be established.

The fact that radiographs were not standardized is a major limitation; however, we believe that by combining the radiographic signs we took into account, which are easy to establish, and combining them with the presence of clinically significant findings, the true incidence of relevant FAI could be established. Another consideration is length of followup, which should be taken into account, especially considering the changing nature of the developing acetabulum, which does not fully develop until early adulthood [12].

\section{Conclusions}

We determined the frequency with which clinically relevant FAI occurs after an innominate osteotomy for the treatment of acetabular dysplasia to be $12 \%$; approximately one in 10 hips undergoing an innominate osteotomy presented clinically relevant FAI. We also determined that a change in the acetabular index greater that $20^{\circ}$ was an independent risk factor for developing FAI when performing an innominate osteotomy for the treatment of acetabular dysplasia. When FAI was present in a cohort of patients of similar characteristics, the clinical outcome was worse than when it was not present.

Our results are not meant to discourage surgeons from performing innominate osteotomies in the treatment of acetabular dysplasia because this is a long-standing treatment, which has proven to have excellent results. However, we believe that our results should add to the understanding of the normal balance of hip physiology. Overcorrection should be avoided when performing an innominate osteotomy for the treatment of acetabular dysplasia because it can create iatrogenic FAI and have an adverse effect on outcome.

A better understanding of the three-dimensional nature of the acetabulum and the change in the relationship with the femoral head after performing an innominate osteotomy will help improve the outcome by reducing the rate of impingement.

Acknowledgments We thank Nelson Cassis MD, FACS, for insight and the cases of the patients studied.

\section{References}

1. Abraham E, Gonzalez MH, Pratap S, Amirouche F, Atluri P, Simon P. Clinical implications of anatomical wear characteristics in slipped capital femoral epiphysis and primary osteoarthritis. $J$ Pediatr Orthop. 2007;27:788-795.

2. Allen D, Beaulé PE, Ramadan O, Doucette S. Prevalence of associated deformities and hip pain in patients with cam-type femoroacetabular impingement. $J$ Bone Joint Surg Br. 2009;91:589-594.

3. Anderson LA, Gililland J, Pelt C, Linford S, Stoddard GJ, Peters $\mathrm{CL}$. Center edge angle measurement for hip preservation surgery: technique and caveats. Orthopedics. 2011;34:86. 
4. Bardakos NV, Villar RN. Predictors of progression of osteoarthritis in femoroacetabular impingement: a radiological study with a minimum of ten years follow-up. J Bone Joint Surg Br. 2009;91:162-169.

5. Barnes JR, Thomas SR, Wedge J. Acetabular coverage after innominate osteotomy. J Pediatr Orthop. 2011;31:530-533.

6. Barrett WP, Staheli LT, Chew DEJ. The effectiveness of the Salter innominate osteotomy in the treatment of congenital dislocation of the hip. J Bone Joint Surg Am. 1986;68:79-87.

7. Beaulé PE, Allen DJ, Clohisy JC, Schoenecker PL, Leunig M. The young adult with hip impingement: deciding on the optimal intervention. J Bone Joint Surg Am. 2009;91:210-221.

8. Böhm P, Brzuske A. Salter innominate osteotomy for the treatment of developmental dysplasia of the hip in children: results of seventy-three consecutive osteotomies after twenty-six to thirtyfive years of follow-up. J Bone Joint Surg Am. 2002;84:178-186.

9. Clohisy JC, Beaulé PE, O'Malley A, Safran MR, Schoenecker P. AOA symposium: hip disease in the young adult. Current concepts of etiology and surgical treatment. J Bone Joint Surg Am. 2008;90:2267-2281.

10. Clohisy JC, Carlisle JC, Beaulé PE, Kim YJ, Trousdale RT, Sierra RJ, Leunig M, Schoenecker PL, Millis MB. A systematic approach to the plain radiographic evaluation of the young adult hip. J Bone Joint Surg Am. 2008;90(Suppl 4):47-66.

11. Dora C, Mascard E, Mladenov K, Seringe R. Retroversion of the acetabular dome after Salter and triple pelvic osteotomy for congenital dislocation of the hip. $J$ Pediatr Orthop $B$. 2002;11:34-40.

12. Fabricant PD, Hirsch BP, Holmes I, Kelly BT, Lorich DG, Helfet DL, Bogner EA, Green DW. A radiographic study of the ossification of the posterior wall of the acetabulum: implications for the diagnosis of pediatric and adolescent hip disorders. $J$ Bone Joint Surg Am. 2013;95:230-236.

13. Ganz R, Leunig M, Leunig-Ganz K, Harris WH. The etiology of osteoarthritis of the hip: an integrated mechanical concept. Clin Orthop Relat Res. 2008;466:264-272.

14. Ganz R, Parvizi J, Beck M, Leunig M, Notzli H, Siebenrock KA. Femoroacetabular impingement: a cause for osteoarthritis of the hip. Clin Orthop Relat Res. 2003;417:112-120.

15. Jamali AA, Mladenov K, Meyer DC, Martinez A, Beck M, Ganz R, Leunig M. Anteroposterior pelvic radiographs to assess acetabular retroversion: high validity of the 'cross-over-sign.' $J$ Orthop Res. 2007;25:758-765.

16. Kim YJ, Ganz R, Murphy SB, Buly RL, Millis MB. Hip jointpreserving surgery: beyond the classic osteotomy. Instr Course Lect. 2006;55:145-158.

17. Klaue K, Durnin CW, Ganz R. The acetabular rim syndrome: a clinical presentation of dysplasia of the hip. J Bone Joint Surg Br. 1991;73:423-429.
18. Kobayashi D, Satsuma S, Kinugasa M, Kuroda R, Kurosaka M. Does Salter innominate osteotomy predispose the patient to acetabular retroversion in adulthood? Clin Orthop Relat Res. 2014;472:1001-1009.

19. Leunig M, Siebenrock KA, Ganz R. Rationale of periacetabular osteotomy and background work. Instr Course Lect. 2001;50:229-238.

20. Loder RT, Aronsson DD, Weinstein SL, Breur GJ, Ganz R, Leunig M. Slipped capital femoral epiphysis. Instr Course Lect. 2008;57:473-498.

21. Pemberton PA. Pericapsular osteotomy of the ilium for treatment of congenital subluxation and dislocation of the hip. J Bone Joint Surg Am. 1965;47:65-86.

22. Parvizi J, Leunig M, Ganz R. Femoroacetabular impingement. $J$ Am Acad Orthop Surg. 2007;15:561-570.

23. Rab GT. Biomechanical aspects of Salter osteotomy. Clin Orthop Relat Res. 1978;132:82-87.

24. Reynolds D, Jucas J, Klaue K. Retroversion of the acetabulum. A cause of hip pain. J Bone Joint Surg Br. 1999;81:281-288.

25. Salter RB. Innominate osteotomy in the treatment of congenital dislocation and subluxation of the hip. J Bone Joint Surg Br. 1961;43:518-539.

26. Salter RB. Specific guidelines in the application of the principle of innominate osteotomy. Orthop Clin North Am. 1972;3:149156.

27. Sierra RJ, Trousdale RT, Ganz R, Leunig M. Hip disease in the young, active patient: evaluation and nonarthroplasty surgical options. J Am Acad Orthop Surg. 2008;16:689-703.

28. Smith-Petersen MN. Treatment of malum coxae senilis, old slipped upper femoral epiphysis, intrapelvic protrusion of the acetabulum, and coxa plana by means of acetabuloplasty. $J$ Bone Joint Surg. 1936;18:869-880.

29. Tannast M, Zheng G, Anderegg C, Burckhardt K, Langlotz F, Ganz R, Siebenrock KA. Tilt and rotation correction of acetabular version on pelvic radiographs. Clin Orthop Relat Res. 2005;438:182-190.

30. Tönnis D. Surgical treatment of congenital dislocation of the hip. Clin Orthop Relat Res. 1990;258:33.

31. Wang CW, Wu KW, Wang TM, Huang SC, Kuo KN. Comparison of acetabular anterior coverage after Salter osteotomy and Pemberton acetabuloplasty: a long-term followup. Clin Orthop Relat Res. 2014;472:1001-1009.

32. Wiberg G. Studies on dysplastic acetabula and congenital subluxation of the hip joint. With special reference to the complication of osteoarthritis. Acta Chir Scand. 1939;83(Suppl 58):28-38. 